\title{
A Study on the Problem of Villager's Self-governance Under the Population Hollowisation
}

\author{
Shenxin Ye ${ }^{1}$, Yaxuan Chen ${ }^{2}$ \\ ${ }^{1}$ School of Economics and Management, Zhejiang University of Science and Technology, Hangzhou, China \\ ${ }^{2}$ School of Foreign Languages, Zhejiang University of Science and Technology, Hangzhou, China \\ Email address: \\ 2089786603@qq.com (Shenxin Ye), yaxuanchen@163.com (Yaxuan Chen)
}

\section{To cite this article:}

Shenxin Ye, Yaxuan Chen. A Study on the Problem of Villager's Self-governance Under the Population Hollowisation. Science Innovation. Vol. 8, No. 2, 2020, pp. 38-42. doi: 10.11648/j.si.20200802.14

Received: February 8, 2020; Accepted: April 8, 2020; Published: May 19, 2020

\begin{abstract}
The acceleration of urbanization, industrialization and marketization are fundamentally changing the traditional rural society as well as the social structure and ideology of China, prompting the rural population to constantly flow and migrate to cities. At the meantime, the traditional concept of rural area is also increasingly updated and even subverted, seriously affecting the effect of villagers' self-governance. Therefore, started from the level of subject, the research explores the economic dilemma and the dilemma of democratic rights of villagers' self-govemance under the background of population hollowisation from the angle of subject construction, and analyzes the practical dilemma of villagers' self-govemance from three aspects including autonomous subject, the foundation of autonomous economy, and democratic management and democratic supervision. With the methods of documental analysis, questionnaire, field research in D, S, X village of J county in Zhejiang China, and with the theory of Deliberative Democracy and the HCM-Human Capital being taken as theoretical basis, the research finds that villagers' self-governance is confronted with predicaments of the absence of autonomous subjects, the weak foundation of the autonomous economy, the formalization of democratic management and democratic supervision. In response to the above predicaments, this paper holds that these problems can be addressed effectively through the following four countermeasures. Firstly, rural economy should be developed greatly and rapidly so that the villagers who flowed to cities can be encouraged to return to rural areas. Secondly, a new type of autonomous subject should be fostered with the purpose of improving the effectiveness of villagers' self-governance. Thirdly, the rural public services have to be improved to a high level so that the gap between urban and rural public services can be narrowed. Finally, the content realization of autonomous governance should be optimized for the long-term significance of villagers' self-governance.
\end{abstract}

Keywords: Population Hollowisation, Villagers' Self-governance, Countermeasures

\section{人口空心化背景下村民自治问题研究}

叶沈欣 $^{1}$, 陈亚轩 ${ }^{2}$

1 浙江科技学院, 经济与管理学院, 杭州, 中国

2浙江科技学院, 外国语学院, 杭州, 中国

邮箱

2089786603@qq.com (叶沈欣), yaxuanchen@163.com(陈亚轩)

摘要: 城市化、工业化和现代化正从根本上改变中国传统的社会结构和思想观念,尤其改变着传统农村社会,促使农村人 口不断地向城市流动、迁移,同时传统的农村观念也日益更新甚至遭到了颠覆，严重影响村民自治效果。本文基于此， 从主体层面出发，从主体构建角度对人口空心化背景下村民自治的经济困境和民主权利困境进行探讨，对村民自治的 自治主体、自治经济基础和民主管理与民主监督三个方面进行分析。文章主要采用文献分析法和问卷调查法, 通过对 
中国浙江省 $\mathrm{J}$ 县 $\mathrm{D}$ 村、 $\mathrm{S}$ 村、 $\mathrm{X}$ 村的实地调研, 结合协商民主理论和人力资源理论研究, 认为当前农村人口空心化背景下 村民自治面临自治主体缺失、自治经济基础薄弱、民主管理和民主监督形式化的困境。为应对以上困境，应从四个方 面着手: 一是发展农村经济, 吸引外流人口返乡; 二是培育新型自治主体, 以提高村民自治成效; 三是提升农村公共 服务水平，缩小城乡公共服务差距；四是完善自治内容实现形式，从而使村民自治具有长远意义。

关键词：农村人口空心化, 村民自治, 应对策略

\section{1. 基本概念与相关理论基础}

\section{1. 农村人口空心化}

关于农村空心化的含义，从不同学科研究角度不同。 如周祝平认为, “农村人口“空心化”是指农村青壮年劳动力 大量流人城市, 导致农村人口下降和农村青壮年人口比例 下降, 农村剩下的人口大多数是老人、妇女和儿童” [1]; 刘远风认为“农村空心化是农村劳动力、资本及其他生产 要素大量流向城市, 导致农村社会边缘化、农村经济调敝 的一种经济社会现象” [2]。总的来说, 学者依据各自研 究角度对农村人口空心化赋予不同概念, 但大都提炼出了 农村人口空心化的共性。而依据本文选题, 本文重点偏于 农村空心化中的“人口空心化”, 故将农村人口空心化定义 为: 农村青壮年人口大量流出致使农村社会基础、农业生 产、治理主体基础弱化。

\section{2. 村民自治}

“村民自治”一词最早在我国1982年的《宪法》中被提及。 之后的《中华人民共和国村委组织法》虽是为确保村民自治 的开展而颁布, 却仍未对村民自治的概念作出具体定义。即 便如此, 学术界对于村民自治的定义大都是从这两部法律中 推导形成的。例如, 徐勇认为, “村民自治, 即村民通过村 民自治组织依照法律处理本村事物, 是农村基层人民群众自 治 [3] ”。何振华认为, “村民自治是农民依法管理基层社 会生活方面的事务 [4] ”。于建嵘指出, “村民自治是广大 农民群众直接行使民主权利, 依法办理自己的事情, 实行自 我管理、自我教育、自我服务的一项基本社会政治制度 [5]”。 结合各方因素，可将村民自治定义为：村民结合自身利益， 根据相关法律授权, 按照民主方式建立自治体系, 以实现自 我管理、自我教育和自我服务的基层群众自治制度。

\section{3. 协商民主理论}

协商民主理论兴起于西方但在中国同样适用。在党的 领导下, 协商民主已深深植根于中国特色社会主义的历史 和现实, 具有鲜明的本土化特征和强大的生命力, 其实质 是实现和加速公民对政治的有序参与。习近平强调, 社会 主义协商民主不是局限于某个领域, 而应该是全方位的。 它应该在全国各地推广, 而不应该仅限制在某一个层级 [6]。在第十九次中国共产党代表大会上, 又细化提出 了, 要以加强协商民主制度建设为基础, 完善制度程序和 群众参与实践, 确保人民群众在日常政治生活中有积极深 入参与的权利 [7]。故此, 社会主义协商民主发展到了 新的高度, 在本文的探讨中可予以借鉴意义。

\section{4. 人力资本理论}

舒尔茨在其著作《论人力资本投资》中认为: 物质资 本指物质产品上的资本，而人力资本则是体现在人身上的 资本, 即对生产者进行教育、职业培训等支出及其在接受 教育时的机会成本等的总和, 表现为蕴含于人身上的各种 生产知识、劳动与管理技能以及健康素质的存量总和 [8]。 对于村民自治的局面，村民的基本知识、技能等自治能力 可以作为一种发挥重要作用的资本; 村民本身具有的异质 性可以保障想法的全面性; 对村民进行教育、培训等手段 可以提高其在村民自治过程中决策的正确性。由此可见人 力资本理论在村民自治中可起借鉴意义。

\section{2. 调查}

\section{1. 调查方法}

\subsection{1. 文献分析法}

文献分析法是指通过对收集到的某方面的文献资料 进行研究, 以探明研究对象的性质和状况, 并从中引出自 己观点的分析方法。笔者收集并整理了国内外关于农村人 口空心化和村民自治的多种文献资料, 熟悉并掌握了相关 的研究状况, 为本文研究奠定了理论基础。

\subsection{2. 问卷调查法}

针对拟定的相关问题和国内外相关调查成果, 编制调 查问卷。采取对 $\mathrm{J}$ 县 $\mathrm{D}$ 村、 $\mathrm{S}$ 村、 $\mathrm{X}$ 村走访方式发放调查问 卷, 以反映出村民内心感受到或分析了解到的现实问题, 体现了结果的普遍性。共发放调查问卷150份, 其中D村 67 份, S村34份, X村49份, 回收138份。

\section{2. 问卷调查基本情况}

被调研者基本情况如下：被调查者男性占 $54.3 \%$, 女 性占 $45.7 \%$, 由于各村多数人口外出谋生, 被调查者年龄 主要集中在 46 岁及以上。从文化程度来看, 没上过学的和 仅上过小学的占 $85 \%$ 以上, 文化程度为高中及以上仅占 $5.8 \%$ 。由此可见农村人口空心化的现状, 为下文调查村民 自治的困境提供依据。

\section{3. 人口空心化背景下村民自治的困境}

\subsection{1. 村民自治主体弱化}

村民自治中, 村民是自治的主体, 其参与程度直接影 响村民自治的进程。但近年来也有不少问题不断凸显, 诸 如“形式化”“制度空转”“悬浮性”“失落的自治”等, 村民自 
治实践遭遇瓶颈 [9]。在调查中, 我们也发现, 所调查 的三个村庄存在村民自治主体缺失, 参与积极性弱的问题。 调查村村民未充分了解村民自治的概念, 民主意识淡薄。 从调查结果来看, 仅有 $13.1 \%$ 的人了解《村民委员会组织 法》（见表1），大部分村民对此法的研究仅停留在知晓 民主选举等表面知识, 对于自治的内容和政策所知甚少。 村民自治旨在使“村委会逐渐摆脱了乡村政府的管制, 成 为独立的群众自治组织, 使广大农民群众成为农村管理的 主体。”[10］自治主体对于自治概念淡薄极大阻碍了后 续民主权利行使的正确性及行使权利的力度。且村民参与 村务管理的频率不高, 在人口空心化背景下村民更着重于 管理自身活动, 对村务管理积极性不高。“村两委唱主调, 响应者胗零”直接导致了村干部对治理的独断性。村民自 治意识能力受村民文化程度的影响, 而人口空心化背景下 村民文化素质普遍不高, 通过深入访谈可了解到, 调查村 的村主任和村支书文化程度也仅是高中水平。组织文化在 团体中起重要的影响, 村民整体文化素质偏低, 加上交通 不便, 直接导致了相对狭险的社会视野和落后的思想观念, 极大阻碍了村庄民主自治的进程。结合资料分析发现, 村 民自治意识淡薄除村民文化素质偏低这一显性因素外, 还 受到层级分明的封建文化的影响及村内组织建设不完善 的影响。

表1 变量“您对村委组织法的熟悉程度”描述性统计。

\begin{tabular}{lll}
\hline & 人数 & 百分比 \\
\hline 了解 & 18 & $13.1 \%$ \\
部分了解 & 83 & $60.1 \%$ \\
不了解 & 37 & $26.8 \%$ \\
\hline
\end{tabular}

\subsection{2. 村民自治经济基础薄弱}

村民自治作为我国农村基层民主的一种主要形式, 尽 管政府的主导作用非常重要, 但经济基础始终是一项重要 的制约因素。一般来说, “村民参与自治的积极性, 在一 定程度上取决于他们对参与自治所能得到的预期收益的 判断” [11]。因此, 村民自治要高质量运行, 必须要有 一定的经济基础作支撑。村民自治的经济基础是指村民自 治运行所必需的物质资源。人口空心化农村多数地处交通 不便、信息闭塞的偏远地段，农村经济发展不足。据下表 2 和表 3 关于村民的家庭年收入和收入途径来看, 调查村经 济发展仍以农业为主, 小农经济经营方式, 留守村民家庭 年收入在 5 万元以上仅占 $26.8 \%$ 。村中村民大批量种植水稻, 此年收入可说明水稻种植在调查村并不合理, 所带来的经 济收益低且人力资本花费较大。村庄信息闭塞, 村民种植 的农作物跟风现象突出, 农产品整体效益低下。加上交通 运输、人力、时间等成本, 许多农产品并未进入市场进行 销售，农民很大程度上面临亏损风险。

表2 变量“您家庭的年收入”描述性统计。

\begin{tabular}{lll}
\hline & 人数 & 百分比 \\
\hline 1.5 万元以下 & 16 & $11.6 \%$ \\
$1.5-3.5$ 万元 & 32 & $23.2 \%$ \\
$3.5-5$ 万元 & 53 & $38.4 \%$ \\
5 万元以上 & 37 & $26.8 \%$ \\
\hline
\end{tabular}

表3 变量“您家庭的主要收入来源”描述性统计。

\begin{tabular}{lll}
\hline & 人数 & 百分比 \\
\hline 务农 & 95 & $68.8 \%$ \\
外出务工 & 17 & $12.4 \%$ \\
个体经营 & 6 & $4.3 \%$ \\
亲人救济 & 20 & $14.5 \%$ \\
\hline
\end{tabular}

\subsection{3. 民主管理和民主监督形式化}

村民自治是指“我国广大农民群众依法在农村实行民 主选举、民主决策、民主管理、民主监督的过程”［12］。 民主管理贯穿于村民自治的全过程, 而民主监督是村民自 治的重要保障, 有利于促进村民自治规范、高效地运行, 农村的各方面工作都应该实行民主管理并接受民主监督。 然而由于人口空心化背景下农村大量青壮年人口流失, 加 之留守村民文化程度不高, 村民自治意识削弱。就下表4 的调查结果来看, 尽管有 $12.3 \%$ 的村民经常参加村务管理, 但剩余村民极少参与甚至不参与村务管理。这说明人口空 心化背景下村民有民主意识但参与度较低。通过进一步走 访发现, 大部分村民不会参与监督村内公共事务。笔者在 调查中与村民交流得知, 村民选择不去监督公共事务大多 数是因“不想多管闲事”、“说了也不会有效”和“怕得罪人” 的顾虑。表 5 和表 6 显示村务按时公开的村庄仅占 $3.6 \%$, 多 数村庄村务公开不频繁, 且仅追求形式化, 使村民对各自 村庄村务公开的满意度不高。加之村民民主意识薄弱, 许 多村存在村委会代替村民决定村中重大事务, 侵犯了村民 的合法权益。由上述调查结果可见, 受留守村民个人素质、 能力、个人理性选择等因素影响, 村民自治中的民主管理 和民主监督趋于形式化。

表4 变量“您参加过村务管理吗”描述性统计。

\begin{tabular}{lll}
\hline & 人数 & 百分比 \\
\hline 经常参加 & 17 & $12.3 \%$ \\
很少参加 & 87 & $63.1 \%$ \\
从未参加 & 34 & $24.6 \%$ \\
\hline
\end{tabular}

表5 变量“你们村村务公开的时间”描述性统计。

\begin{tabular}{lll}
\hline & 人数 & 百分比 \\
\hline 按时公开 & 5 & $3.6 \%$ \\
有时公开 & 28 & $20.3 \%$ \\
很少公开 & 53 & $38.4 \%$ \\
从不公开 & 32 & $23.2 \%$ \\
不清楚 & 20 & $14.5 \%$ \\
\hline
\end{tabular}

表6 变量“您对你们村村务公开的满意程度”描述性统计。

\begin{tabular}{lll}
\hline & 人数 & 百分比 \\
\hline 很满意 & 6 & $4.3 \%$ \\
满意 & 47 & $34.1 \%$ \\
较满意 & 67 & $48.6 \%$ \\
很不满意 & 18 & $13.0 \%$ \\
\hline
\end{tabular}

\section{3. 人口空心化下村民自治的对策}

\section{1. 发展农村经济, 吸引外流人口返乡}

政府要加强对各地农村经济现状的了解, 在政策上予 以大力支持。郭正林教授在研究四川省乐山市市中区棉竹 
镇高项村这一个案时曾选取经济增长与分配作为乡村治 理的制度绩效的评估标准之一 [13]，即农村经济可从某 一角度影射乡村治理的状态, 由此可见发展农村经济的必 要性。从调查中可得知, 现人口空心化农村仍以小农经济 为主导经济, 故政府需联合各地各单位增派知识型、技术 型人才, 以当地资源环境为基础, 优化农业产业结构。种 植收益高、产量高的农作物, 并将生产经营方式从集约型 向粗放型转变。根据当地气候、地理等因素, 发展特色农 产品。这样, 一方面可以使有劳动能力但无工作的留守村 民就业, 开拓他们的就业渠道, 另一方面, 可以吸引在外 农民和精英人才看到发展契机, 回乡创业就业。其次, 发 展壮大集体经济。农村的集体经济能力在一定程度上决定 着村民自治组织服务农村的能力, 决定着村民自治的凝聚 力和影响力。因此, 要争取开办自己的集体企业, 发展壮 大农村集体经济。

\section{2. 培育新型自治主体}

留守村民是村民自治的主体, 其自治意识很大程度上 影响村民自治成效和进程。然而, 从上文调查结果也可看 出, 留守村民大多年龄偏大, 文化素质偏低, 受封建文化 影响, 其思想较保守, 更关注自身利益。因此, 对留守村 民进行自治概念的普及、教育和培训, 提高村民的民主意 识是关键。政府安排人员定期对村中干部进行知识普及, 再由干部回乡用村民会议等方式进行宣讲, 为村民解决疑 难, 调动村民的参与积极性。为吸引更多精英回乡领导, 还需建立和完善村干部激励机制, 既保障村干部工作的积 极性，同时也可提供村民自治的效率。

\section{3. 提升农村公共服务水平}

十八大报告明确指出, 现在社会矛盾明显增多, 教育、 就业、社会保障、医疗、住房、生态环境、安全生产、社 会治安、执法司法等关系群众切身利益的问题较多 [14], 而这些问题在人口空心化村庄犹为突出, 村内留守村民大 多年龄较大, 且留守老人和留守儿童居多。各村公共服务 等基础设施条件较差, 是导致大量农村人口外流的原因之 一。缩小城乡公共服务差距可引导人员回流，营造更好的 村民自治氛围。一方面, 政府需加强对农村基础设施建设 的服务力度, 确保水电的覆盖范围, 推进网络等信息基础 建设, 加快各村道路建设。另一方面, 政府需着力于农村 的公共服务建设, 加强培育乡村教师, 保障农村初级教育; 确保农村卫生所人员数量合理及医疗设施完善, 提升医疗 水平; 积极开展农民职业教育, 培育新型农民, 带动人口 回流。

\section{4. 完善自治内容实现形式}

“以治理与善治理论为视角, 乡村治理目标是善治, 即乡村善治, 它应该包含以下价值性要素：民主、自治、 透明、法治、回应、责任、和谐、公正、参与、稳定等。” [15] 故从长远的治理角度来看, 乡村自治内容的实现形 式应与善治的要素结合。村委要健全村民民主选举方式, 对候选代表进行综合考核, 建立切实可靠的干部考核奖惩 制度, 定期组织村民对村干部开展综合评议, 保证干部工
作的积极性和可靠性; 完善民主决策程序, 保障村务公开 的及时性、透明型，凡是村内重大事务都需和村民共同商 议，积极落实村民的知情权、监督权、决策权。同时，乡 镇政府需减少对村内事务的干预, 重大决策以农民为先, 广泛征求农民意见。

\section{4. 结论}

村民自治是中国共产党领导我国农民建设中国特色 社会主义民主政治的伟大创造, 是时代发展的结果。其作 为我国基层民主的重要实现形式, 已基本适应了农村经济 体制改革的要求。

然而, 通过调查发现, 在人口空心化村庄, 村民自治 还存在诸多问题。第一, 在自治主体方面, 人口空心化背 景下的村民自治存在自治主体弱化的问题。除村民文化素 质偏低这一因素影响外, 层级分明的封建文化及村内组织 不完善也同样导致了这个问题。第二, 在经济基础方面, 人口空心化背景下的村民自治经济基础薄弱。其原因主要 是受多地处偏远地段的人口空心化村庄的交通及信息传 播速度制约, 村民种植农作物跟风现象严重, 效益低下, 且多数农作物无法进入市场进行交易。第三，在民主落实 方面，人口空心化背景下的村民自治民主管理和民主监督 趋于形式化。村民民主意识薄弱, 行使自我权利存在诸多 顾虑, 村委会代为治理等, 都使广大村民游离于村民自治 的范畴之外。

为使村民自治在人口空心化村庄中取得良好成效，需 从多方面寻求对策。如, 在经济方面, 政府根据村庄实际 情况予以帮助的同时, 也需鼓动村内能人领导村民发展壮 大集体经济; 在自治方面, 要对村民进行知识普及, 培养 新型自治主体; 在公共服务方面, 要加强基础设施建设, 提升公共服务水平; 在自治内容方面, 要完善民主机制, 保障落实“四个民主”等。

尽管在人口空心化背景下的村民自治还存在诸多问 题，但在国家、政府和农村的共同努力下，这些问题终会 解决, 村民自治必将到达新高度。

\section{参考文献}

[1] 周祝平.中国农村人口空心化及其挑战 [ J ] . 人口研 究,2008,32(2):45.

[2] 刘远风.刘易斯拐点后的中国农村空心化治理 [ J ] . 经济经 纬,2014,31(1):32.

[3] 徐勇.中国农村研究 [ M ] . 北京: 中国社会科学出版 社,2012:124-135.

[4] 何振华.我国农村基层群众自治制度存在的问题与对策 $[\mathrm{J}]$. 商品与质量: 理论研究,2012(3):24-28.

［5］于建嵘.村民自治：价值和困境一一兼论《中华人民共和国 村民委员会组织法》的修改 [J]. 学习与探索,2010(4):73. 
[6] 中共中央关于加强社会主义协商民主建设的意见 [ EB/OL ] .(2015-02-09) [ 2020-03-17 ] . 新华网 : http://news.xinhuanet.com./politics/2015-02-09/c-1114310670 .htm.

[7] 习近平.决胜全面建成小康社会夺取新时代中国特色社会 主义伟大胜利一在中国共产党第十九次全国代表大会上的 报告 [N].人民日报,2017-10-28.

[8] [美]西奥多·W·舒尔茨. 论人力资本投资 $[\mathrm{M}$ ]. 吴珠华等译, 北 京:北京经济学院出版社,1990年版.

[9] 徐勇.实践创设并转换范式:村民自治研究的回顾与反思 一写在第一个村委会诞生 35 周年之际 $[\mathrm{J}]$.中国社会 科学评价,2015(3):4-12.

[10] 袁金辉.冲突与参与: 中国乡村治理改革 30 年[M].郑州: 郑州大学出版社,2008:109.
[11] 康燕.新时期村民自治的问题及研究对策——包头市石 拐区后营子为例 [D].内蒙古大学硕士论文,2012.

[12] 徐勇.村民自治的成长:行政放权与社会发育一1990 年代 以来中国村民自治发展困境的反思 $[\mathrm{J}]$. 华中师范大学学 报,2005,44(2):2-8.

[13] 郭正林.乡村治理及其制度绩效评估: 学理性案例分析 [J]. 华中师范大学学报（人文社会科学版）,2004(4):25-32

[14] 胡锦涛. 在中国共产党第十八次全国代表大会上的报告 ［OL ] .(2012-11-17) [ 2020-03-17 ] . 新 华 网 :http://news.xinhuanet.com/18cpcnc/2012-11/17c_1137116 65.htm.

[15] 郑茂刚.通过乡村善治构建和谐乡村 [ J ] . 科学社会主 义,2007(4):14-15. 